\title{
The impact of filling level resolved: Capillary-assisted evaporation of water for adsorption heat pumps
}

\author{
Franz LANZERATH, Jan SEILER, Meltem ERDOGAN, Heike SCHREIBER, Matthias STEINHILBER, André \\ BARDOW*
}

\author{
RWTH Aachen University \\ Institute of Technical Thermodynamics \\ 52070 Aachen, Germany \\ phone: $+4924180-95381$ \\ fax: +4924180-92255 \\ email: andre.bardow@ltt.rwth-aachen.de
}

\begin{abstract}
Evaporation of water at low pressures is usually limited by low heat transfer coefficients. Poor heat transfer can severely restrict the performance of cooling devices such as adsorption heat pumps and chillers. The heat transfer can be enhanced by using structures such as fins and porous coatings. These structures provide capillary action to wet the heat exchanger tubes surface with a thin water film leading to high heat transfer coefficients. Hence, the evaporation performance strongly depends on the thickness of the thin water film and consequently on the filling level of the heat exchanger. In this work, the evaporation performance is investigated systematically for horizontal copper tubes with macroscopic fin structures, microporous coatings and the combination of both structures. In particular, an experimental setup is introduced to study continuously varying filling levels. The influence of evaporation temperature and heat flow on the heat transfer coefficient is studied. The heat transfer is found to depend strongly on the filling level and the temperature, whereas the heat flow has no significant influence at the studied measurement conditions. It is shown that the heat transfer is directly proportional to the tube surface wetted by capillary action. The evaporation performance of thermally-coated tubes can reach heat transfer coefficients similar to falling film evaporators. Thus, the presented tube structures allow for improved evaporator designs for future adsorption heat pumps using water as refrigerant.
\end{abstract}

\section{KEYWORDS}

film evaporation; filling level; capillary action; water; adsorption chiller; adsorption heat pump;

\section{INTRODUCTION}

Adsorption-based energy systems can provide efficient heating and cooling by using low temperature solar or waste heat sources [1,2]. Possible applications include adsorption-based storage [3], heat pumps [4] and chillers [5]. Besides improving efficiency, current research aims at increasing the specific cooling power (SCP). To achieve high SCP values, compact and light components with good heat transfer characteristics are crucial. Next to the adsorber itself the second most important component for high SCP values is the evaporator [6].

The evaporator determines the vapor pressure in the adsorption process. The pressure level in the evaporator directly affects the kinetics and the maximum loading of the adsorption process. Thus, poor evaporators can drastically limit the performance of adsorption-based energy systems $[7,8]$.

Evaporation is particularly challenging for water, the most commonly used refrigerant in adsorption chillers $[9,10]$ : At common evaporation temperatures of $5-10{ }^{\circ} \mathrm{C}$ water vapor pressures are very low and therefore the favorable mechanism of nucleate boiling requires high wall superheat of up to $20 \mathrm{~K}$ [11-14]. To avoid the efficiency losses due to large temperature differences, nucleate boiling can usually not be exploited. Instead, natural convection determines the heat transfer resulting in low heat transfer coefficients. As a consequence, evaporation requires large surfaces, reducing the $\mathrm{SCP}$ of the cooling device.

DOI: 10.1016/j.applthermaleng.2016.03.052

(C) 2016. This manuscript version is made available under the CC-BY-NC-ND 4.0 license http://creativecommons.org/licenses/by-nc-nd/4.0 
To enhance the heat transfer, several researchers proposed macroscopic structures such as fins [15] and microscopic structures such as coatings [16]. Finned tubes are already used in adsorption heat pumps [17]. These structured surfaces provide capillary action generating a thin water film on the evaporator surface, which increases the evaporation performance. For fin structures, this effect can be investigated analytically [18,19], whereas for porous coatings mainly experimental investigations have been performed [16,20]. Xia et al. [15] and Schnabel et al. [21] showed for discrete filling levels that both kinds of structures can lead to significant improvement of the evaporation process.

In this work, macroscopic and microscopic structures for heat transfer surfaces are systematically investigated. A promising thermal coating is presented which greatly improves the heat transfer. Preliminary data has been shown in a conference presentation [22]. We resolve in detail the performance of coated finned tubes as a function of the filling level of the evaporator. A key contribution of this work is the introduction of a novel experimental setup to resolve the impact of the filling level continuously. The measurements with continuously resolved filling level show that the heat transfer coefficient increases strongly with lower filling level. The optimal filling level is precisely identified and allows exploiting the full potential of the structured heat exchangers in adsorption chillers. We further analyze the active heat transfer area and the impact of evaporation temperature and of heat flow on the heat transfer coefficient. The measurements show that the heat transfer coefficient depends on the temperature whereas the heat flow has no significant influence.

In section 2 we present the investigated heat exchangers and the novel experimental setup. In sections 3 and 4, we compare different structures and provide a detailed analysis of the most promising heat exchanger. In section 5, the results are summarized and conclusions are presented.

\section{MATERIALS AND METHODS}

\subsection{Investigated heat exchangers tubes}

Four heat exchanger tubes made of copper are investigated in this study (Figure 1). As reference for the investigated microscopic and macroscopic structures, an ordinary uncoated plain (UP) tube is characterized. The tube represents one of the simplest possible heat exchanger geometries. As no capillary action is to be expected for the UP tube it defines the lower bound for comparison of heat transfer characteristics. As second tube, a commercial uncoated finned tube (UF) with an additional inner turbulence structure is investigated as state-of-the-art geometry in evaporators for adsorption chillers (Chen et al., 2010). The heat-transfer-enhancing effect of the macroscopic fin structure is quantified. As tubes 3 and 4, both the (UP) and (UF) tubes are provided with a porous copper coating to study its effect on the evaporation performance. The resulting coated plain tube (CP) allows for the isolated investigation of the porous coating whereas the coated finned tube (CF) reveals the effect of combining both structures. Geometries of the tubes are listed in Table 1.

Table 1: Geometries of the plain and finned tubes used in this study

\begin{tabular}{lccccccc}
\hline & $\begin{array}{c}\text { length } \\
L(\mathrm{~m})\end{array}$ & $\begin{array}{c}\text { inner } \\
\text { diameter } \\
d_{\mathrm{i}}(\mathrm{mm})\end{array}$ & $\begin{array}{c}\text { outer } \\
\text { diameter } \\
d_{\mathrm{o}}(\mathrm{mm})\end{array}$ & $\begin{array}{c}\text { fin } \\
\text { height } \\
H_{\mathrm{f}}(\mathrm{mm})\end{array}$ & $\begin{array}{c}\text { fin } \\
\text { thickness } \\
\delta_{\mathrm{f}}(\mathrm{mm})\end{array}$ & $\begin{array}{c}\text { fin } \\
\text { distance }\end{array}$ & $\begin{array}{c}\text { inner } \\
\Delta_{\mathrm{f}}(\mathrm{mm})\end{array}$ \\
$\begin{array}{l}\text { turbulence } \\
\text { structure }\end{array}$ \\
\hline finned tube & 2.0 & 13.3 & 18.8 & 1.5 & 0.3 & 1.04 & yes \\
\hline
\end{tabular}



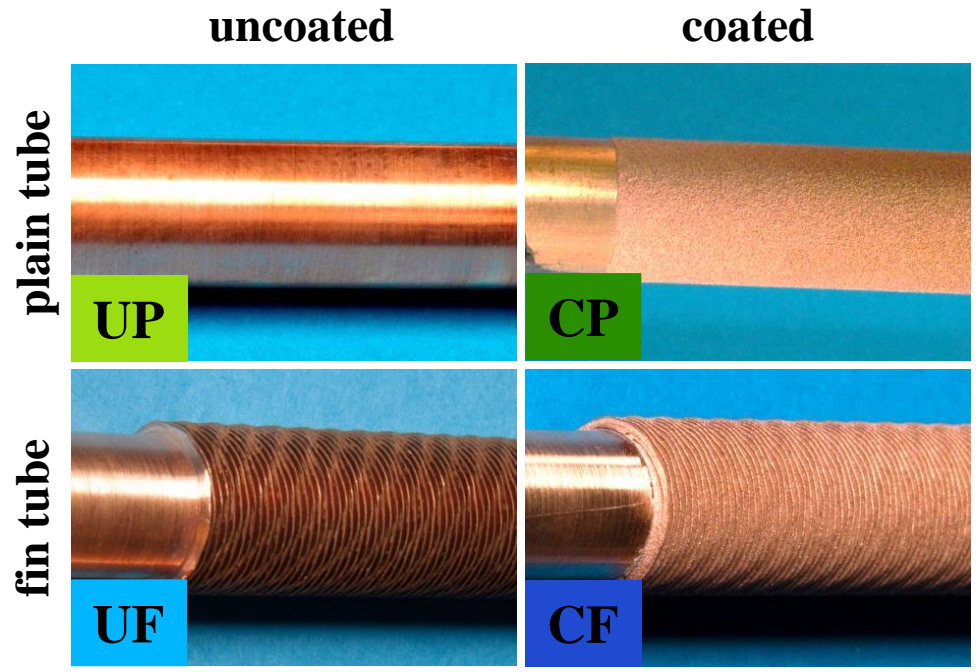

Figure 1: Photos of the investigated tubes: the uncoated plain tube (UP) and uncoated finned tube (UF) on the left and the coated plain tube $(\mathrm{CP})$ and coated finned tube $(\mathrm{CF})$ on the right.

\subsection{Experimental setup}

The experimental setup is designed to determine the overall heat transfer coefficient, the $U$-value, during evaporation as a function of the filling level. A strong influence of the filling level due to capillary action is expected [15]. In the experimental setup, different tube types can be mounted horizontally and investigated at evaporation temperatures in the range from $5{ }^{\circ} \mathrm{C}$ to $20^{\circ} \mathrm{C}$. The evaporator consists of a vacuum vessel containing the investigated tubes. The evaporator is connected to a vacuum pump to lower the system pressure and activate the evaporation process (Figure 2, top). The pressure-induced evaporation process is similar to the situation in adsorption chillers except that the vacuum pump removes water steam at a constant volume flow rate from the evaporator. A water circuit connected to a thermostat provides the thermal energy required for the evaporation process.
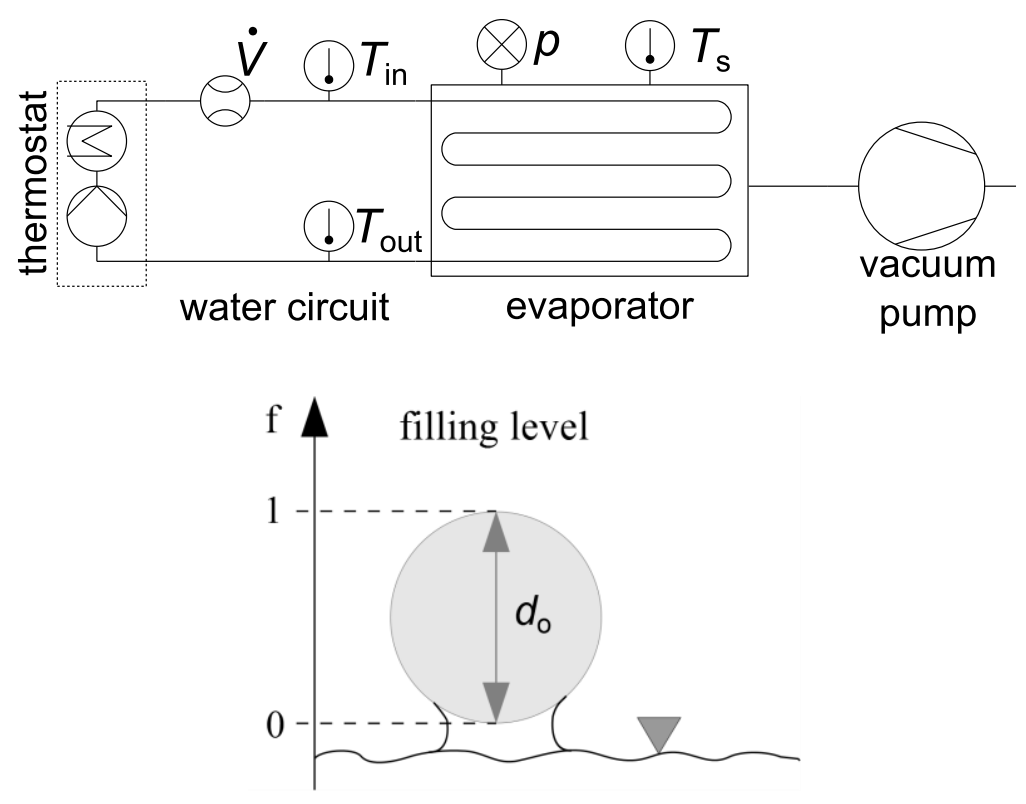

Figure 2: Experimental setup (top) and definition of the filling level $f$ (bottom) 
The measurement proceeds as follows: At the beginning, the tubes are flooded with water and the vacuum pump is connected to the evaporator. No water is refilled during the measurement, thus, the filling level $f$ decreases continuously with time due to the evaporation of water. The measurement finally ends when the tubes fall dry and are no longer in contact with water. The filling level is defined as $f=1$ when the water surface is right at top of the tube and as $f=0$ when the water surface is at bottom of the tube (Figure 2, bottom). Due to capillary action, negative values of $f$ can occur as indicated in figure 2 .

To evaluate the $U$-value of the evaporation process, we measure temperatures of the water circuit inlet ( $T_{\text {in }}$ ), of the outlet $\left(T_{\text {out }}\right)$ and of the water steam $\left(T_{\mathrm{s}}\right)$ as well as the volume flow $\dot{V}$ and the steam pressure $p$. Then, the $U$-value can be determined from:

$$
U=\frac{\dot{Q}}{A \Delta_{\ln } T}
$$

$\dot{Q}$ is the heat flow, $A$ and $\Delta_{\ln } T$ are the reference surface and temperature difference of the evaporation process, respectively. The reference surface $A$ is chosen as the enveloping cylindrical surface with the outer diameter $d_{\mathrm{o}}$ of the tubes, i.e.,

$$
A=\pi d_{\mathrm{o}} L .
$$

The enveloping cylindrical reference surface was chosen to calculate the $U$-value, since it accounts for the required space of the tubes, which is important for sizing aspects. For the plain tubes, the cylindrical reference surface A is equal to the actual outer surface of the plain tubes. For the fin tubes, the diameter $d_{\mathrm{o}}$ includes the height of the fins to account for the space required to install the fin tubes. Thereby, the cylindrical reference surface is, however, smaller than the actual outer surface of the fin tubes as the surface increase by the fins is not full taken into account. The actual surface area is about 2.8 times larger than the reference surface for the fin tubes.

For the coated plain and fin tubes (CP and CF, respectively), the same reference surface as for the uncoated tubes (UP and UF, respectively) is used.

The temperature difference between the water circuit and the steam is described by the logarithmic mean temperature difference [23]:

$$
\Delta_{\text {ln }} T=\frac{T_{\text {in }}-T_{\text {out }}}{\ln \frac{T_{\text {in }}-T_{\mathrm{s}}}{T_{\text {out }}-T_{\mathrm{s}}}}
$$

where $T_{\mathrm{s}}$ denotes the steam temperature.

Since the time-derivative of the internal energy of the water inside the tubes is very low ( $<2.5 \mathrm{~W}$, cf. Appendix A) for all conducted experiments, we can assume quasi-steady-state conditions and calculate the heat flow from the temperature difference between inlet and outlet:

$$
\dot{Q}=\dot{V} \rho c\left(T_{\text {in }}-T_{\text {out }}\right) \text {. }
$$

Here, $\dot{V}$ is the volume flow of the water circuit, $\rho$ the density and $c$ the heat capacity of the water.

Substituting equations ( 2 ), ( 3 ) and ( 4 ) into equation ( 1 ) leads to the following expression for the $U$-value:

$$
U=\frac{\dot{V} \rho c}{\pi d_{\mathrm{o}} L} \ln \frac{T_{\text {in }}-T_{\mathrm{s}}}{T_{\text {out }}-T_{\mathrm{s}}}=\frac{\dot{V} \rho c}{\pi d_{\mathrm{o}} L} \ln \frac{\Delta T_{\text {in }}}{\Delta T_{\text {out }}} .
$$

The uncertainty of the $U$-value $\left(\sigma_{U}\right)$ is evaluated with respect to sensor uncertainties using Gaussian error propagation according to JCGM [24] and includes the uncertainties of the measured temperature differences $\sigma_{\Delta T_{i}}$ and the volume flow $\sigma_{\dot{V}}$ : 


$$
\sigma_{U}=\sqrt{\sum_{i}\left(\frac{\partial U}{\partial \Delta T_{i}} \sigma_{\Delta T_{i}}\right)^{2}+\left(\frac{\partial U}{\partial \dot{V}} \sigma_{\dot{V}}\right)^{2}}
$$

For all measurements, the uncertainty $\sigma_{U}$ is below $15 \%$. However, a small systematic error due to transient effects adds to the total uncertainty. In particular at the beginning and the end of the evaporating process, the temperatures are varying and the evaluation of the $U$-value according to equations 1 and 4 is incomplete. The additional systematic error due to assuming quasi-steady-state conditions is estimated to maximal $10 \%$ by analyzing the temperature gradients of $T_{\mathrm{in}}, T_{\mathrm{out}}$ and $T_{\mathrm{s}}$. The analysis follows the derivation shown in Appendix 1 for the inner tube [25]. Because of similar temperature gradients in all measurements, the additional error is systematic and the comparison of the resulting $U$-values is expected to be hardly influenced.

The $U$-value is related to the inner and outer heat transfer coefficients $h_{\mathrm{i}}$ and $h_{\mathrm{o}}$ according to the following expression for circular tubes [23]:

$$
U A=\pi L[\underbrace{\frac{1}{h_{\mathrm{i}} d_{\mathrm{i}}}}_{\text {(I) }}+\underbrace{\frac{1}{2 \lambda_{\mathrm{Cu}}} \ln \left(\frac{d_{\mathrm{o}}-2 H_{\mathrm{f}}}{d_{\mathrm{i}}}\right)}_{(\text {II) }}+\underbrace{\frac{1}{h_{\mathrm{o}} d_{\mathrm{o}}}}_{(\mathrm{III})}]^{-1} .
$$

Term (I) on the right hand side of equation ( 6 ) describes the convective heat transfer inside the tube, term (II) the heat conduction through the tube wall and term (III) the evaporation at the outside of the tube. Heat conduction through the wall is described by the tube geometry (Table 1) and the thermal conductivity $\lambda_{\mathrm{Cu}}$ of the copper wall. The inner heat transfer coefficient $h_{\mathrm{i}}$ can be calculated with a correlation used by Thome [26]

$$
h_{\mathrm{i}, \text { Thome }}=C \frac{\lambda_{\mathrm{w}}}{d_{\mathrm{i}}} \operatorname{Re}^{0,8} \operatorname{Pr}^{1 / 3}\left(\frac{\eta_{\text {bulk }}}{\eta_{\text {wall }}}\right)^{0.14}
$$

with the heat conductivity $\lambda_{\mathrm{w}}$ of water, the Reynolds number $R e$ and the Prandtl number Pr. By neglecting the influence of the fraction of the dynamic viscosity at the mean temperature of the fluid $\eta_{\text {bulk }}$ and of the dynamic viscosity of the fluid at the wall $\eta_{\text {wall }}$, the resulting correlation for the inner heat transfer coefficient $h_{\mathrm{i}}$ becomes

$$
h_{\mathrm{i}}=C \frac{\lambda_{\mathrm{w}}}{d_{\mathrm{i}}} \operatorname{Re}^{0,8} \operatorname{Pr}^{1 / 3} .
$$

The constant $C$ has a value of 0.027 for smooth tubes and can be adjusted for tubes with inner structure. For the inner tube structure of the investigated finned tubes (UF and CF), we experimentally determined a value of $C=0.05$ which is in the typical range (0.027 to 0.078) for turbulence structures [27].

With knowledge of the inner heat transfer coefficient $h_{\mathrm{i}}$, the outer heat transfer coefficient $h_{\mathrm{o}}$ can be calculated from equation ( 7 ). However, the uncertainty of the outer heat transfer coefficient $h_{\mathrm{o}}$ is relatively high due to the combined uncertainty of $U$ (about $15 \%$ ) and $h_{\mathrm{i}}$ (about $25 \%$ [28]).

\section{COMPARISION OF THE TUBE STRUCTURES}

All tube structures are characterized with the same experimental setting, to compare their evaporation performance. The evaporation temperature is determined by the inlet temperature $T_{\text {in }}=15^{\circ} \mathrm{C}$ of the tubes. By lowering the pressure and thus the saturation temperature with the vacuum pump, wall superheats in the range of a few Kelvins are achieved. These are typical conditions of adsorption chillers. The volume flow of the water circuit is set to $\dot{V}=161 / \mathrm{min}$ resulting in high inner heat transfer coefficients $h_{\mathrm{i}}$ (cf. eq. ( 9 )) for the plain tubes $\left(7,600 \mathrm{~W} / \mathrm{m}^{2} \mathrm{~K}\right.$ ) and the finned tubes with turbulence structure $\left(13,400 \mathrm{~W} / \mathrm{m}^{2} \mathrm{~K}\right)$. A high inner heat transfer coefficient is important to avoid a limitation of the $U$-value (cf. eq. ( 7 )) and thus allows to identify the effect of the outer structure on the overall heat transfer.

Measured $U$-values for all 4 tubes are shown as a function of the filling level in Figure 3 . The maximal $U$-values as well as the calculated corresponding inner and outer heat transfer coefficients are listed in Table 2. The continuous 
measurement of the $U$-value as a function of the filling level allows for a detailed analysis of the heat transfer characteristics and the precise identification of the optimal filling level for operation in adsorption chillers.

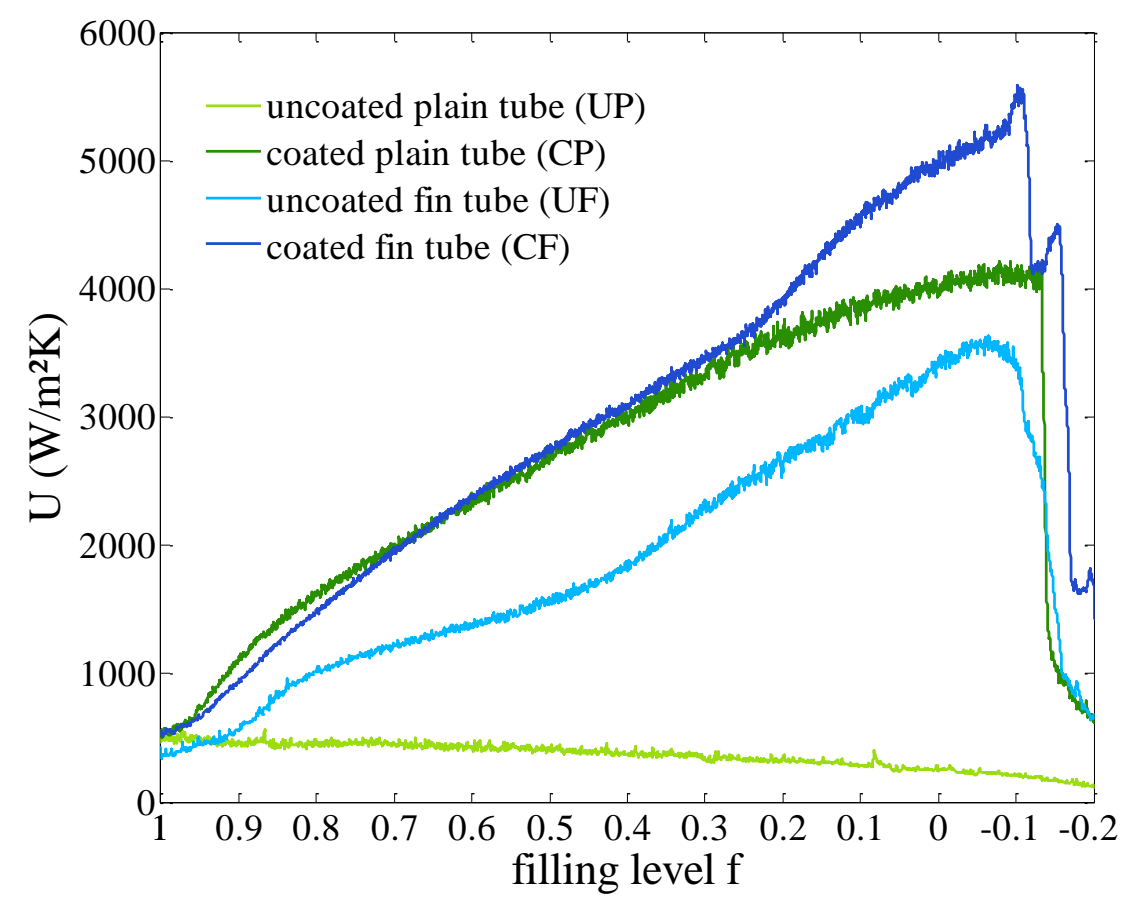

Figure 3: Overall heat transfer coefficient, the $U$-value, of all investigated tubes at $15^{\circ} \mathrm{C}$ evaporation temperature as a function of the filling level $f$.

\subsection{Uncoated plain tube (UP)}

The uncoated plain tube (UP) shows the lowest $U$-value of all examined tubes. The overall heat transfer coefficient is highest at the beginning (filling level $f=1$ ) with a value of $U_{\mathrm{UP}}^{\max }=500 \mathrm{~W} / \mathrm{m}^{2} \mathrm{~K}$. The $U$-value decreases with falling filling level because the heat transfer occurs only at the submerged tube surface that decreases with filling level. There is no sign for capillary action wetting the free surface and influencing the heat transfer. Thus, the outer heat transfer coefficient of approximately $h_{\mathrm{o}, \mathrm{UP}}^{\max }=550 \mathrm{~W} / \mathrm{m}^{2} \mathrm{~K}$ limits the evaporation process.

\subsection{Uncoated finned tube (UF)}

The addition of fins to an uncoated plain tube leads to a completely different behavior as demonstrated by the uncoated finned tube (UF): At high filling level, the UF tube shows the same low $U$-values as the plain tube and is also limited by natural convection. With decreasing filling level, the tube exhibits much higher $U$-values with a maximum of $U_{\mathrm{UF}}^{\max }=3500 \mathrm{~W} / \mathrm{m}^{2} \mathrm{~K}$. The corresponding maximum outer heat transfer coefficient is as high as $h_{\mathrm{o}, \mathrm{UF}}^{\max }=5700 \mathrm{~W} / \mathrm{m}^{2} \mathrm{~K}$. This value is more than 10 times higher than the maximum of the uncoated plain tube. Part of this increase can be explained by the larger surface area provided by the fins, since the enveloping cylindrical surface is used as the reference surface of the tube and does not include the fin surface (cf. 2.2 Experimental setup). However, even assuming perfect fin efficiency, the additional surface of the fins would only account for a factor of 2.8 and could thus only account for less than a third of the measured increase in the maximum outer heat transfer coefficient. The additional increase of heat transfer with falling water level can be attributed to the exposed surface above the water filling level. Capillary action creates a thin water film on the fin-structured surface with high heat transfer ability. The thin water film offers low thermal resistance as well as convective transport mechanisms to replace the evaporated water. Both mechanisms are expected to promote heat transfer. The highest $U$-value occurs at a relative filling level $f<0$, i.e. the water filling level has already dropped below the tubes, as capillary action still provides water for evaporation. Eventually, the water loses contact to the tube resulting in a sharp decrease of the heat transfer coefficient and breakdown of the evaporation process. Therefore, in practice, the filling level in adsorption chillers should be slightly above $f=0$ to continuously provide water for the evaporation process and to ensure efficient and reliable operation. 


\subsection{Coated plain tube (CP)}

The coated plain tube (CP) shows a heat transfer characteristic similar to the uncoated finned tube (UF), but with even higher $U$-values with a maximum of $U_{\mathrm{CP}}^{\max }=4100 \mathrm{~W} / \mathrm{m}^{2} \mathrm{~K}$. Thus, the coating increases the total heat transfer up to 8 times compared to the uncoated plain tube. The tube also shows a continuous increase of heat transfer with falling water level. This increase is only due to the increasing outer heat transfer coefficient with a peak value of $h_{\mathrm{o}, \mathrm{CP}}^{\max }=$ $11300 \mathrm{~W} / \mathrm{m}^{2} \mathrm{~K}$ since the inner heat transfer with $h_{\mathrm{i}}=7600 \mathrm{~W} / \mathrm{m}^{2} \mathrm{~K}$ at $\dot{V}=16 \mathrm{l} / \mathrm{min}$ remains constant during the experiment. Although the $U$-value is restricted by the inner heat transfer $\left(h_{\mathrm{i}}<h_{\mathrm{o}}\right)$, the coating enables high $U$-values comparable to falling film evaporators [29].

Table 2: Maximum heat transfer coefficients for the considered tube types at $15^{\circ} \mathrm{C}$ : Overall heat transfer coefficient $\boldsymbol{U}$, inner heat transfer coefficient $h_{\mathrm{i}}$ from eq. ( 9 ) and outer heat transfer coefficient $h_{\mathrm{o}}$ from eq. ( 7 ).

\begin{tabular}{lccc}
\hline Tube type & $\boldsymbol{U}$ & $\begin{array}{c}\boldsymbol{h}_{\mathbf{i}} \\
\left(\mathbf{W} / \mathbf{m}^{\mathbf{2}} \mathbf{K}\right)\end{array}$ & $\begin{array}{c}\boldsymbol{h}_{\mathbf{0}} \\
\left(\mathbf{W} / \mathbf{m}^{\mathbf{2}} \mathbf{K}\right)\end{array}$ \\
\hline Uncoated plain tube (UP) & 500 & 7600 & 550 \\
Uncoated finned tube (UF) & 3500 & 13400 & 5700 \\
Coated plain tube (CP) & 4100 & 7600 & 11300 \\
Coated finned tube (CF) & 5500 & 13400 & 13800 \\
\hline
\end{tabular}

\subsection{Coated finned tube (CF)}

The combination of both kinds of structures (CF: microporous coating and macroscopic fins) leads to the highest total heat transfer of all examined tubes. The maximum $U$-value of $5500 \mathrm{~W} / \mathrm{m}^{2} \mathrm{~K}$ is $50 \%$ higher than for the uncoated finned tubes and 11 times higher than for the ordinary plain tubes. Again, the heat transfer coefficient increases continuously with falling filling level due to the thin film evaporation and exhibits its maximum of $h_{\mathrm{o}, \mathrm{CF}}^{\max }=13800 \mathrm{~W} / \mathrm{m}^{2} \mathrm{~K}$ at the lowest filling level. The coating more than doubles the outer heat transfer coefficient compared to the uncoated fins (Table 2).

\subsection{Comparison with literature}

In earlier works, Xia and Schnabel measured evaporation at discrete filling levels [15,20]. Our results confirm the increasing evaporation performance of finned tubes with decreasing filling level. The outer heat transfer coefficient of the uncoated finned tube (UF) is similar to the measurements of Xia et al. [15] who determined slightly higher values $\left(\mathrm{h}_{\mathrm{o}}=6000\right.$ to $\left.7000 \mathrm{~W} / \mathrm{m}^{2} \mathrm{~K}\right)$ for a different finned tube structure at a filling level of $f=0.25$.

Schnabel \& Witte [16] achieved a 2.5-times higher total heat transfer with galvanic coating of plain tubes compared to uncoated tubes. However, according to these authors, the $U$-value has possibly been limited by inner heat transfer so that the potential of the galvanic coating had not been fully exploited.

The combination of coating and fins was also studied by Schnabel et al. [20] using titanium oxide and enamel coatings to improve the heat transfer of finned tubes. However, only small improvements $(<15 \%)$ of evaporation performance was observed. According to Schnabel et al. again inner heat transfer probably limited evaporation. By contrast, the thermal coating $(\mathrm{CF})$ examined in this work doubles the outer heat transfer compared to the uncoated finned tubes (UF) and thereby enhances the total heat transfer by more than $50 \%$.

Hence, the varying results for different tube geometries and coatings demonstrate the difficult endeavor to find the optimal structure for heat transfer. Nevertheless, the combination of micro and macro structures studied in this work already exhibits high evaporation performance and provides prospect for new evaporator designs. The coated finned tubes presented in this work can reduce the size of evaporators by one order of magnitude compared to uncoated plain tubes.

\section{DETAILED ANALYSIS OF COATED FINNED TUBES}

The coated finned tubes (CF) show the highest outer heat transfer coefficient of $h_{\mathrm{o}, \mathrm{UF}}^{\max }=13,800 \mathrm{~W} / \mathrm{m}^{2} \mathrm{~K}$. In this section, an extensive analysis of the total heat transfer is performed at different temperatures and heat flows. Furthermore, we analyze the active evaporation surface. 


\subsection{Influence of temperature and heat flow on the heat transfer coefficient}

The influence of evaporation temperatures and heat flows on the $U$-value is investigated as adsorption heat pumps operate at varying temperatures and have large changes of heat flows due to the cyclic operation. For this purpose, the coated finned tube (CF) is characterized at inlet temperatures $T_{\text {in }}$ of $5,10,15$ and $20^{\circ} \mathrm{C}$. The influence of the temperature on the overall heat transfer is shown in Figure 4 and the maximum achieved heat transfer coefficients are listed in Table 3.

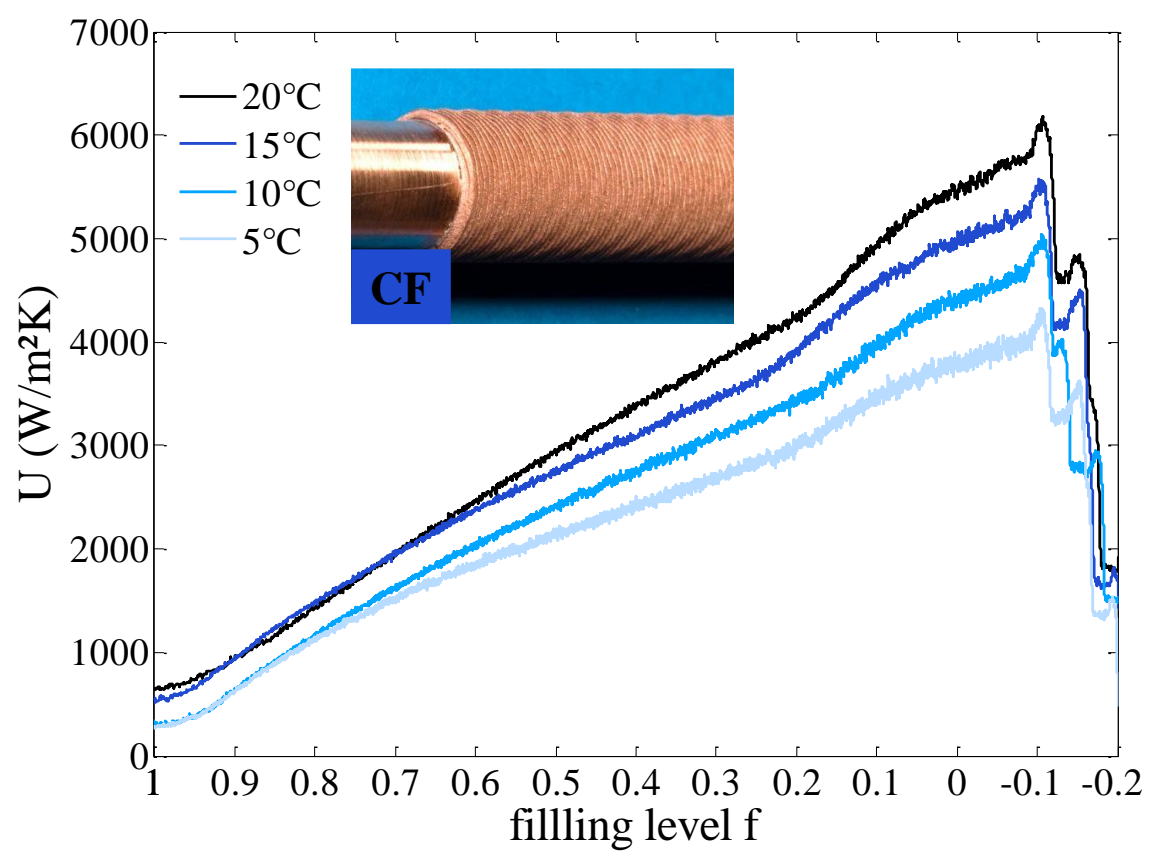

Figure 4: Influence of evaporation temperature on the $U$-value of the coated finned tube (CF) as a function of the filling level $f$.

The results clearly show a positive influence of temperature on the heat transfer coefficient, i.e. the $U$-value increases approximately $500 \mathrm{~W} / \mathrm{m}^{2} \mathrm{~K}$ per $5 \mathrm{~K}$ at low filling levels. This is due to an increase of both the inner and outer heat transfer coefficients. The higher temperature and altered properties of water result in higher Reynolds numbers and enhance the inner heat transfer by about $\Delta h_{\mathrm{i}}=1000 \mathrm{~W} / \mathrm{m}^{2} \mathrm{~K}$ per $5 \mathrm{~K}$. The increase of the outer heat transfer coefficient is even higher with $\Delta h_{0}=2000 \mathrm{~W} / \mathrm{m}^{2} \mathrm{~K}$ per $5 \mathrm{~K}$ at optimal filling level, which leads to a limitation of the $U$-value by the inner heat transfer coefficient at evaporation temperatures of $15^{\circ} \mathrm{C}$ and higher. The higher temperatures lead to lower viscosity of water which may promote the evaporation process. Besides, the higher evaporation temperatures lead to higher evaporation pressures and thus higher vapor densities which also may enhance heat transfer. This effect is also common for the evaporation mechanisms of natural convection and nucleate boiling [23,30].

The improved evaporation could also be due to different heat flows in the measurements, as higher heat fluxes usually result in higher heat transfer coefficients for evaporation processes [23,30]. For all temperatures, the measurements are conducted at the same volume flow rate $\dot{V}_{S}$ of the vacuum pump. Since the density of the water vapor $\rho_{\mathrm{s}}(T)$ and the enthalpy of vaporization $\Delta_{\text {vap }} h(T)$ are temperature dependent, the resulting heat flow also varies with temperature:

$$
\dot{Q}=\dot{m}_{\mathrm{s}} \Delta_{\mathrm{vap}} h=\dot{V}_{\mathrm{s}} \rho_{s}(T) \Delta_{\mathrm{vap}} h(T) .
$$


Therefore, additional measurements are conducted at evaporation temperatures of $15^{\circ} \mathrm{C}$ and $20^{\circ} \mathrm{C}$ with two different heat flows. The heat flows are adjusted by throttling the volume flow $\dot{V}_{s}$ of the vacuum pump. The additional measurements are shown in Figure 5.

Table 3: Maximum heat transfer coefficients $U, h_{\mathrm{i}}$ and $h_{\mathrm{o}}$ at different evaporation temperatures $T$ for the coated finned tube $(\mathrm{CF})$.

\begin{tabular}{ccccc}
\hline $\boldsymbol{T}$ & $\begin{array}{c}\boldsymbol{p} \\
\left({ }^{\circ} \mathbf{C}\right)\end{array}$ & $\begin{array}{c}\boldsymbol{U} \\
\left(\mathbf{W} / \mathbf{m}^{\mathbf{2}} \mathbf{K}\right)\end{array}$ & $\begin{array}{c}\boldsymbol{h}_{\mathbf{i}} \\
\left(\mathbf{W} / \mathbf{m}^{\mathbf{2}} \mathbf{K}\right)\end{array}$ & $\begin{array}{c}\boldsymbol{h}_{\mathbf{0}} \\
\left(\mathbf{W} / \mathbf{m}^{\mathbf{2}} \mathbf{K}\right)\end{array}$ \\
\hline $\mathbf{5}$ & 8.7 & 4250 & 11500 & 9200 \\
$\mathbf{1 0}$ & 12.3 & 4950 & 12500 & 11800 \\
$\mathbf{1 5}$ & 17.1 & 5500 & 13400 & 13800 \\
$\mathbf{2 0}$ & 23.4 & 6100 & 14400 & 16200 \\
\hline
\end{tabular}

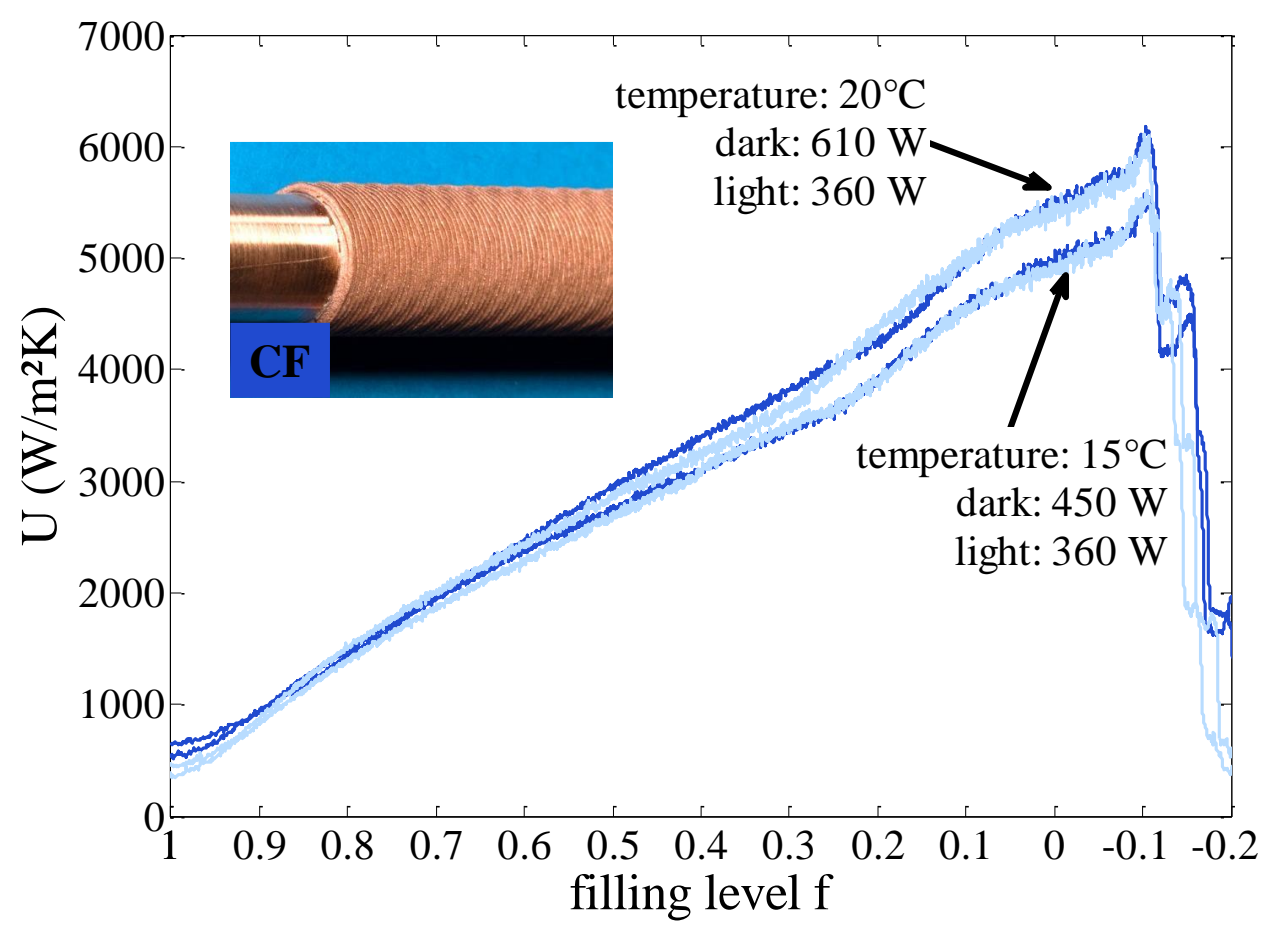

Figure 5: $U$-value of the coated finned tube (CF) for different evaporation temperatures and heat flows as a function of the filling level $f$.

The measurements at reduced heat flows (light curves) coincide with the measurements at original heat flows (dark curves) at same temperature. Therefore, no influence of the heat flow is found within the measurement accuracy. Thus, the increased $U$-value for increasing temperature can be attributed to altered water properties and higher vapor pressure / densities as discussed before.

Comparing these results with measurements of Xia et al. [15] leads to some discrepancy: Although Xia et al. show a small increase of $h_{\mathrm{o}}$ with increasing temperature of about 250 to $500 \mathrm{~W} / \mathrm{m}^{2} \mathrm{~K}$ per $5 \mathrm{~K}$, they found a decrease of the heat transfer coefficient with increasing wall superheat. In contrast, our measurements do not indicate an influence of the wall superheat. At different heat flows and thus at different wall superheat (c.f. eq. ( 1 )), the same $U$-value is observed for fixed evaporation temperature (Figure 5). Moreover, evaporation mechanisms like natural convection and nucleate boiling show increasing heat transfer coefficients with increasing wall superheat [23,30]. Further investigations are needed to clarify these observations. 


\subsection{Active evaporation surface}

In order to deepen the understanding of the heat transfer in the experiments, we analyze the active surface of the tube, i.e. the part of the surface where the evaporation is assumed to take place. For this purpose, we introduce the new reference surface $A_{f}$ into equation ( 1 ) (c.f. Figure 6):

$$
A_{f}=A \cdot \frac{\gamma(f)}{\pi}
$$

with

$$
\cos (\gamma)=\frac{f-0.5}{0.5}
$$

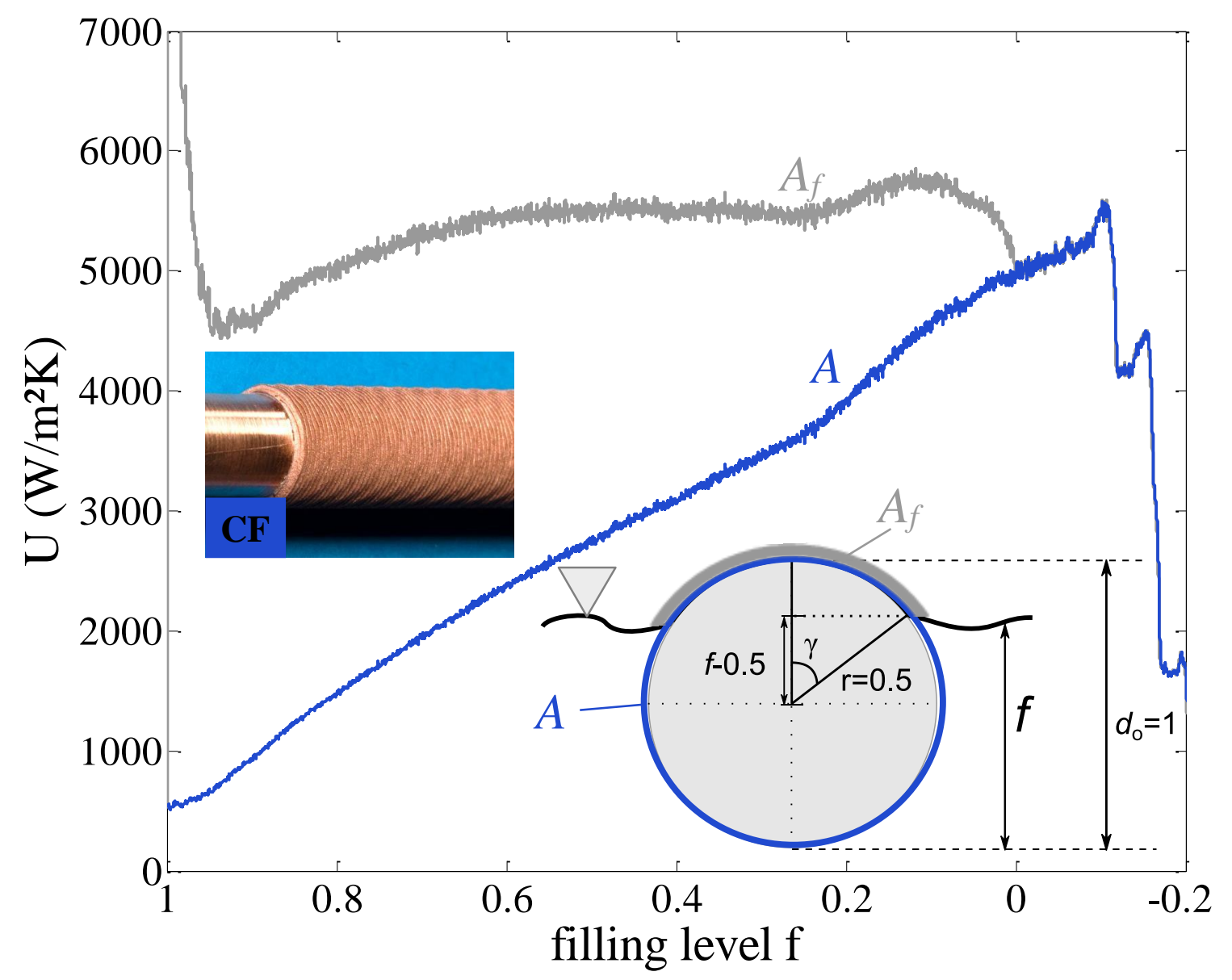

Figure 6: $U$-value of the coated finned tube (CF): $\boldsymbol{U}$ and $\boldsymbol{U}_{\boldsymbol{f}}$ for reference surfaces $A$ and $A_{f}$ (c.f. equation (2) and (9)) as a function of the filling level $f$.

This new reference surface $A_{f}$ depends on the filling level $f$ and accounts only for the surface above the filling level. This area is supposed to be wetted by a thin water film and to be governing the evaporation process. The corresponding $U$-value is denoted $U_{f}$. By analyzing the $U$-value $U_{f}$ of the new reference surface $A_{f}$, the submerged part of the tube is neglected and the resulting value describes the average heat transfer coefficient of the surface $A_{f}$ above the water level. The result is shown in Figure 6.

The new defined overall heat transfer coefficient $U_{f}$ shows an approximately constant value of $5500 \mathrm{~W} / \mathrm{m}^{2} \mathrm{~K}$ for a broad range of the filling level $f$. Only at the beginning for filling levels close to $f=1$, the $U$-value tends to infinity 
since the definition of $A_{f}$ has a singularity at $f=1$. For filling levels smaller than 0 , the definition of both surfaces $A$ and $A_{f}$ is identical as the tube is completely above the water level. Therefore, both curves are identical for $f \leq 0$.

The constant $U_{f}$-value of $5500 \mathrm{~W} / \mathrm{m}^{2} \mathrm{~K}$ observed is strong evidence for the assumption that the surface above the water level is covered by a water film and determines the evaporation process. The submerged surface apparently does not participate significantly in the evaporation process.

\section{SUMMARY AND CONCLUSION}

In this work, a systematic investigation of structured tubes is presented for capillary-assisted evaporation of water at low pressures. Heat exchanger tubes with macroscopic fin structures as well as microporous coating are experimentally characterized. Furthermore, the combination of both structures is investigated. Measurements of the total heat transfer coefficient $U$ are conducted at continuously varying filling levels of the evaporator. The results show a strong dependence of the heat transfer coefficient on the filling level. Highest $U$-values are found at the lowest filling level before the tubes fall dry. A detailed analysis shows that the evaporation takes place at the free surface of the tubes whereas the submerged parts of the tubes can be neglected in the capillary-assisted evaporation process. Furthermore, a strong dependence of the evaporation temperature on the $U$-value is found while the heat flow of the measurements has no significant influence. The applied thermal coatings greatly improve the heat transfer: coating of plain tubes result in a heat transfer coefficient of $U=4100 \mathrm{~W} / \mathrm{m}^{2} \mathrm{~K}$. This value is higher than for the investigated stateof-the-art finned tube structures with $U=3500 \mathrm{~W} / \mathrm{m}^{2} \mathrm{~K}$. The combination of macroscopic fin structures and microporous coatings leads to further improvements and yields $U$-values of $5500 \mathrm{~W} / \mathrm{m}^{2} \mathrm{~K}$. Compared with ordinary plain tubes $\left(U=500 \mathrm{~W} / \mathrm{m}^{2} \mathrm{~K}\right)$, the heat transfer is 11 -fold. Hence, the combination of macroscopic fin structures and microporous thermal coating can reduce the size of evaporators by one order of magnitude. This renders new evaporator designs possible for compact high performance water evaporators in future adsorption chillers. Our results on the strong impact of the filling level show that the full realization of this potential relies on suitable operation of the evaporator.

\section{ACKNOWLEDGEMENT}

We thank Pallas Oberflächentechnik GmbH \& Co. KG for providing the coated heat exchanger tubes and gratefully acknowledge the financial support from the German Federal Ministry for Economic Affairs and Energy in the Central Innovation Programme for SMEs (ZIM).

\section{NOMENCLATURE}

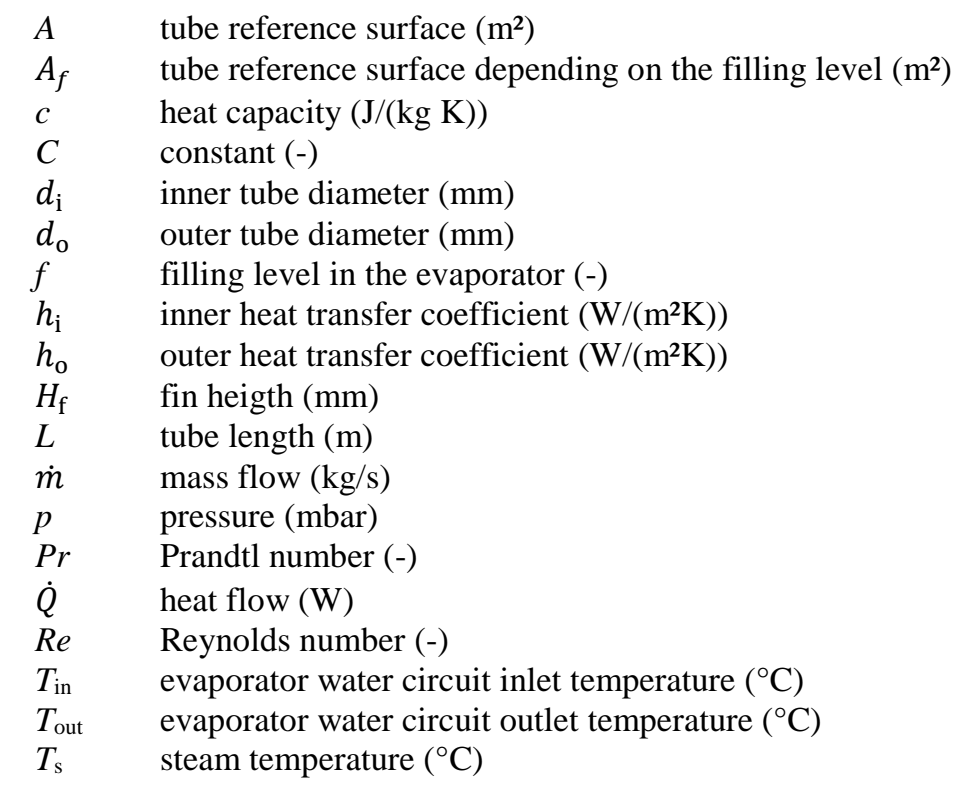




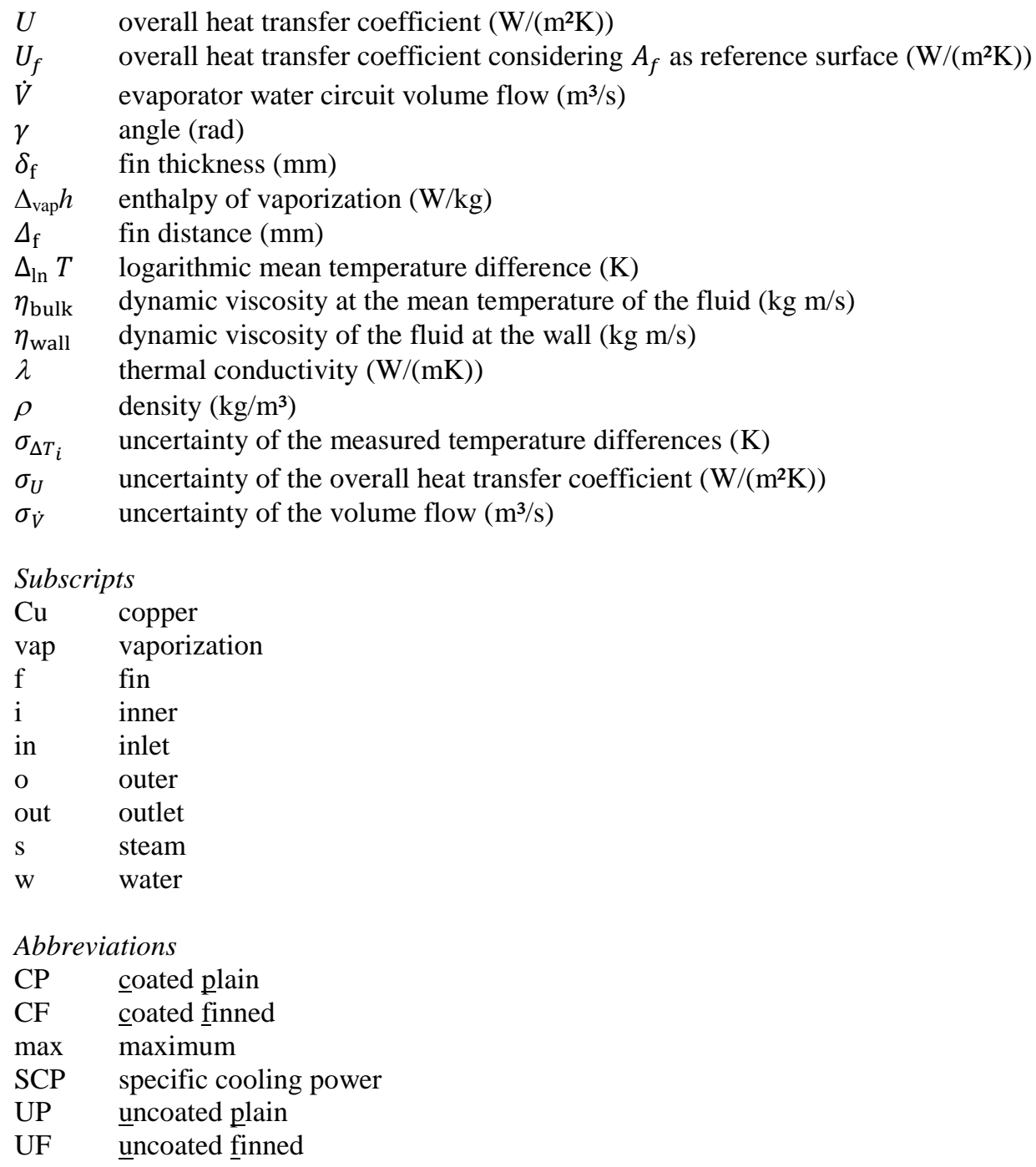

\section{REFERENCES}

[1] R.Z. Wang, Z.Z. Xia, L.W. Wang, Z.S. Lu, S.L. Li, T.X. Li, J.Y. Wu, S. He, Heat transfer design in adsorption refrigeration systems for efficient use of low-grade thermal energy, Energy 36 (2011) 5425-5439.

[2] J. Steven Brown, P.A. Domanski, Review of alternative cooling technologies, Appl. Therm. Eng. 64 (2014) 252-262.

[3] H. Schreiber, S. Graf, F. Lanzerath, A. Bardow, Adsorption thermal energy storage for cogeneration in industrial batch processes: Experiment, dynamic modeling and system analysis, Appl. Therm. Eng.89 (2015) 485-493.

[4] F. Meunier, Adsorption heat powered heat pumps, Appl. Therm. Eng. 61 (2013) 830-836.

[5] R. Best, W. Rivera, A review of thermal cooling systems, Appl. Therm. Eng. 75 (2015) 1162-1175.

[6] F. Lanzerath, U. Bau, J. Seiler, A. Bardow, Optimal design of adsorption chillers based on a validated dynamic object-oriented model, Science and Technology for the Built Environ. 21 (2015) 248-257.

[7] M. Khan, K. Alam, B.B. Saha, A. Akisawa, T. Kashiwagi, Study on a re-heat two-stage adsorption chiller The influence of thermal capacitance ratio, overall thermal conductance ratio and adsorbent mass on system performance, Appl. Therm. Eng. 27 (2007) 1677-1685.

[8] Y.L. Liu, R.Z. Wang, Z.Z. Xia, Experimental performance of a silica gel-water adsorption chiller, Appl. Therm. Eng. 25 (2005) 359-375. 
[9] L.W. Wang, R.Z. Wang, R.G. Oliveira, A review on adsorption working pairs for refrigeration, Renewable and Sustainable Energy Reviews 13 (2009) 518-534.

[10] H. Demir, M. Mobedi, S. Ülkü, A review on adsorption heat pump: Problems and solutions, Renew. and Sustain. Energy Rev. 12 (2008) 2381-2403.

[11] B. Zajaczkowski, T. Halon, Z. Krolicki, Experimental verification of heat transfer coefficient for nucleate boiling at sub-atmospheric pressure and small heat fluxes, Heat Mass Transfer 52 (2016) 205-215.

[12] T. Halon, B. Zajaczkowski, Z. Krolicki, K. Wojtasik, Calculation and experimental verification of heat transfer coefficient for low pressure methanol evaporator, in: ICR 2015 Proceedings: Proceedings of the 24th IIR International Congress of Refrigeration, IIF-IIR, Paris, 2015.

[13] F. Giraud, R. Rullière, C. Toublanc, M. Clausse, J. Bonjour, Experimental evidence of a new regime for boiling of water at subatmospheric pressure, Exp. Therm. and Fluid Science 60 (2015) 45-53.

[15] W.R. McGillis, V.P. Carey, J.S. Fitch, W.R. Hamburgen, Boiling binary mixtures at subatmospheric pressures, in: [1992 Proceedings] Intersociety Conference on Thermal Phenomena in Electronic Systems, 5-8 Feb. 1992, pp. 127-136.

[16] Z.Z. Xia, G.Z. Yang, R.Z. Wang, Experimental investigation of capillary-assisted evaporation on the outside surface of horizontal tubes, Int. J. Heat and Mass Transfer 51 (2008) 4047-4054.

[17] L. Schnabel, K.T. Witte, Water As Refrigerant - Evaporator Development For Cooling Applications, in: Heat Powered Cycles Conference Proceedings, 2009.

[18] C.J. Chen, R.Z. Wang, Z.Z. Xia, J.K. Kiplagat, Z.S. Lu, Study on a compact silica gel-water adsorption chiller without vacuum valves: Design and experimental study, Appl. Energy 87 (2010) 2673-2681.

[19] Z.Z. Xia, G.Z. Yang, R.Z. Wang, Capillary-assisted flow and evaporation inside circumferential rectangular micro groove, Int. J. Heat and Mass Transfer 52 (2009) 952-961.

[10] R.H. Nilson, S.W. Tchikanda, S.K. Griffiths, M.J. Martinez, Steady evaporating flow in rectangular microchannels, Int. J. Heat and Mass Transfer 49 (2006) 1603-1618.

[20] L. Schnabel, K. Witte, J. Kowol, P. Schossig, Vergleich von Verdampferstrukturen für das Kältemittel Wasser, in: Deutsche Kälte-Klima-Tagung 2010 Magdeburg, DKV, Hannover, 2010.

[21] L. Schnabel, K. Witte, J. Kowol, P. Schossig, Evaluation of different evaporator concepts for thermally driven Sorption Heat Pumps and Chillers, in: ISHPC 2011 Proceedings, 2011, pp. 543-552.

[22] F. Lanzerath, M. Erdogan, H. Schreiber, M. Steinhilber, A. Bardow, Combination of finned tubes and thermal coating for high performance water evaporation in adsorption heat pumps, in: ISHPC 2014 Proceedings, 2014.

[23] H.D. Baehr, K. Stephan, Heat and Mass Transfer, 3rd ed., Springer Berlin, Berlin, 2014.

[24] Joint Committee for Guides in Metrology (JCGM), Evaluation of measurement data - Guide to the expression of uncertainty in measurement: JCGM 100:2008. GUM 1995 with minor corrections, 2008, http://www.bipm.org/en/publications/guides/gum_print.html.

[25] F. Lanzerath, Aachener Beiträge zur technischen Thermodynamik: Modellgestützte Entwicklung von Adsorptionswärmepumpen. PhD Thesis, RWTH Aachen University, Mainz, Aachen, 2014.

[26] J.R. Thome, Engineering Data Book III, Wolverine Tube, Inc., 2010.

[27] I. Wolverine Tube, TURBO-CIII Data Sheet, 2009.

[28] W. Dittus, L. Boelter, Heat transfer in automobile radiators of the tubular type, University of California Publications in Engineering 2 (1930) 443-461.

[29] W. Li, X.-Y. Wu, Z. Luo, R.L. Webb, Falling water film evaporation on newly-designed enhanced tube bundles, Int. J. Heat and Mass Transfer 54 (2011) 2990-2997.

[30] Verein Deutscher Ingenieure, VDI-Wärmeatlas, Springer Vieweg, Berlin, 2013.

\section{Appendix}

\section{A Quasi-steady-state assumption}

Here, we present the calculation of the maximum time-derivative of the internal energy $\frac{\mathrm{d} U}{\mathrm{~d} t}$ of the water inside the four tubes for all conducted experiments. For this purpose, we use the measured maximum time-derivative of the average temperature $\frac{\mathrm{d} T_{\text {avg }}}{\mathrm{d} t}$. In order to provide an upper bound, we used the maximum time-derivative of the temperature of all conducted experiments. 
Page 14

$$
\begin{gathered}
\frac{\mathrm{d} U}{\mathrm{~d} t}=4 L \pi\left(d_{\mathrm{i}}\right)^{2} \rho_{\text {water }} c_{\text {water }} \frac{\mathrm{d} T_{\text {avg }}}{\mathrm{d} t} \\
\frac{\mathrm{d} T_{\text {avg }}}{\mathrm{d} t}=\frac{\mathrm{d}\left[\frac{T_{\text {out }}+T_{\text {in }}}{2}\right]_{\max }}{\mathrm{d} t}<2 \times 10^{-3} \frac{\mathrm{K}}{\mathrm{s}} \\
\frac{\mathrm{d} U}{\mathrm{~d} t}<2.5 \mathrm{~W}
\end{gathered}
$$

